SCIENTIFIC LETTER

\title{
Metoprolol prophylaxis against postoperative atrial fibrillation increases length of hospital stay in patients not on pre-operative $\beta$ blockers: the $\beta$ blocker length of stay (BLOS) trial
}

\author{
E Crystal, K E Thorpe, S J Connolly, A Lamy, I Cybulsky, S Carroll, R Roberts, M Gent
}

Heart 2004;90:941-942. doi: 10.1136/hrt.2003.016048

$\mathrm{P}$ ostoperative atrial fibrillation (AF) is a common complication of heart surgery, affecting $20-40 \%$ of patients. In recent guidelines of the American Heart Association and the European Society of Cardiology, $\beta$ blocker (BB) treatment has been recommended as a first line choice for the prevention of postoperative AF. ${ }^{1}$ Although the efficacy of readministration of BB to post-cardiac surgery patients has been evaluated, the effectiveness of prophylactic $\mathrm{BB}$ in patients without prior BB treatment has not been adequately studied.

In order to evaluate whether preoperative $\mathrm{BB}$ use affects the outcome of prophylactic BB treatment after heart surgery, an analysis was performed using the data of the largest double blind, placebo controlled, randomised trial of prophylactic BB treatment (metoprolol) for reduction in hospital length of stay following heart surgery, known as the $\beta$ blocker length of stay (BLOS) study. ${ }^{2}$

In the BLOS study 1000 patients undergoing elective open heart surgery were randomised equally to metoprolol (100$150 \mathrm{mg} /$ day) or double blind placebo, started within 12 hours of arrival in the intensive care unit (ICU) after surgery. The patients were followed for postoperative $\mathrm{AF}$, length of hospital stay, and cost of in-hospital care. A third party payer prospective (Ministry of Health of Canada) was chosen for the cost analysis; costs are quoted in Canadian dollars.

The central question this study addresses is: "Does the therapeutic effect of prophylactic metoprolol use differ according to preoperative BB usage?" Multiple linear regression was used for quantitative outcomes such as length of stay, and multiple logistic regression was used for discrete outcomes such as AF. Tests of interaction were done to assess whether the effect of treatment differed significantly between two different groups of patients. Fisher's exact test and Student's $t$ test (both two sided) were used to compare baseline characteristics between the two preoperative BB usage groups.

\section{RESULTS}

Of 1000 patients enrolled in the BLOS study, 806 patients $(81 \%)$ received a $\mathrm{BB}$ preoperatively and $194(19 \%)$ did not ( $\mathrm{BB}$ and no $\mathrm{BB}$ groups, respectively). The groups were similar in age, sex, and history of AF (table 1). More patients in the $\mathrm{BB}$ group had received diltiazem before surgery $(34.5 \% \mathrm{v}$ $16.3 \%, \mathrm{p}<0.001$ ) and more patients in the $\mathrm{BB}$ group underwent coronary artery bypass grafting (CABG), compared to the no BB group (who were more likely to have other valve or combined surgery) (92.1\% v 55.7\%, p < 0.001). The haemodynamic response to prophylactic metoprolol was different in the two groups (table 1). The no BB patients showed a significantly greater decrease in cardiac index and a greater negative chronotropic effect with metoprolol.

In the whole study population, prophylactic metoprolol reduced the percentage of patients in whom AF occurred from $39 \%$ to $31 \%$ (relative risk reduction of $20 \%, p<0.01$ ). In the $\mathrm{BB}$ group, metoprolol decreased the occurrence of postoperative $\mathrm{AF}$ from $40.1 \%$ to $29.6 \%$; however, in the no BB group, the risk of AF increased from 35\% to $38.5 \%$ $(p=0.065$, after adjustment for age and type of surgery, $\mathrm{p}=0.3)$.

Abbreviations: $A F$, atrial fibrillation; $B B, \beta$ blocker; $B L O S, \beta$ blocker length of stay; $C A B G$, coronary artery bypass grafting; ICU, intensive care unit

Table 1 Physiologic response to study drug administration

\begin{tabular}{|c|c|c|c|c|c|}
\hline & \multirow[b]{2}{*}{ Pre-operative BB } & \multicolumn{2}{|l|}{ Study drug } & \multirow{2}{*}{$\begin{array}{l}\text { Difference between placebo } \\
\text { and metoprolol }\end{array}$} & \multirow[b]{2}{*}{${ }^{*} \mathrm{p}$ Value } \\
\hline & & Metoprolol & Placebo & & \\
\hline \multicolumn{6}{|c|}{ Change between baseline and 8 hours in ICU } \\
\hline Heart rate & $\begin{array}{l}\text { Yes } \\
\text { No }\end{array}$ & $\begin{array}{l}-2.39(9.80) \\
-5.74(1) .42)\end{array}$ & $\begin{array}{l}-0.41(9.05) \\
1.03(987)\end{array}$ & $\begin{array}{l}1.98(9.44) \\
677(1061)\end{array}$ & 0.0022 \\
\hline \multirow[t]{2}{*}{ Cardiac index } & Yes & $-0.13(0.67)$ & $-0.082(0.64)$ & $0.051(0.66)$ & 0.0018 \\
\hline & No & $-0.34(0.80)$ & $-0.016(0.72)$ & $0.32(0.76)$ & \\
\hline \multirow{2}{*}{ PAWP } & Yes & $0.51(3.32)$ & $-0.45(3.23)$ & $-0.96(3.28)$ & 0.17 \\
\hline & \multicolumn{4}{|c|}{ Change between baseline and day 4} & \\
\hline Heart rate & $\begin{array}{l}\text { Yes } \\
\text { No }\end{array}$ & $\begin{array}{l}-4.27(16.43) \\
-5.93(16.45)\end{array}$ & $\begin{array}{l}4.98(17.20) \\
1.11(14.47)\end{array}$ & $\begin{array}{l}9.25(16.82) \\
7.04(15.46)\end{array}$ & 0.50 \\
\hline
\end{tabular}

Figures are presented as mean and standard deviation of mean

*Unadjusted $p$ values of interaction ( $p$ value tests for an interaction between pre-operative BB use and study drug).

$\mathrm{BB}, \beta$ blocker; ICU, intensive care unit; PAWP, pulmonary artery wedge pressure. 
Table 2 Occurrence of postoperative AF, length of stay in ICU, and total length of stay in hospital

\begin{tabular}{|c|c|c|c|c|c|c|}
\hline & \multirow[b]{2}{*}{ Pre-operative BB } & \multicolumn{2}{|l|}{ Study drug } & \multirow[b]{2}{*}{ Odds ratio } & \multirow{2}{*}{$\begin{array}{l}\text { Difference between } \\
\text { placebo and metoprolol }\end{array}$} & \multirow[b]{2}{*}{ p Value } \\
\hline & & Metoprolol & Placebo & & & \\
\hline \multicolumn{7}{|l|}{ Dichotomous outcomes } \\
\hline \multirow[t]{2}{*}{$\mathrm{AF}$} & Yes & $29.6 \%$ & $40.1 \%$ & 0.63 & & 0.065 \\
\hline & No & $38.5 \%$ & $35.0 \%$ & 1.16 & & \\
\hline \multirow[t]{2}{*}{ Complications $†$} & Yes & $8.8 \%$ & $7.8 \%$ & 1.14 & & 0.99 \\
\hline & No & $12.1 \%$ & $10.7 \%$ & 1.15 & & \\
\hline \multicolumn{7}{|l|}{ Continuous outcomes } \\
\hline \multirow[t]{2}{*}{ ICU stay (hours) } & Yes & $36.1(30.8)$ & $34.9(25.8)$ & & $-1.2(28.5)$ & $0.03 \ddagger$ \\
\hline & No & $53.0(107.8)$ & 31.7 (18.1) & & $-21.3(75)$ & \\
\hline \multirow[t]{2}{*}{ Hospital stay (hours) } & Yes & $149.2(57.2)$ & $152.4(61.7)$ & & $3.3(59.4)$ & $0.002 \ddagger$ \\
\hline & No & $183.4(171.2)$ & $148.0(59.2)$ & & $-35.4(124.9)$ & \\
\hline \multirow[t]{2}{*}{ Hospital cost (C\$) } & Yes & $4755(2040)$ & $4729(1730)$ & & & \\
\hline & No & 5374 (2839) & 4521 (1508) & & & \\
\hline
\end{tabular}

$B B, \beta$ blocker; ICU, intensive care unit

*Unadjusted $p$ values of interaction ( $p$ value tests for an interaction between pre-operative BB use and study drug).

†Complications were: ventricular tachyarrhythmia, stroke, myocardial infarction, embolism, infection, need for a permanent pacemaker, ventilation for $>3$ days or reintubation.

防 value calculated after taking logarithm base 10 .

Overall, metoprolol did not significantly affect either the length of stay in the ICU or length of stay in hospital. However, the effect of prophylactic metoprolol on length of stay differed significantly between patients in the $\mathrm{BB}$ and the no $\mathrm{BB}$ groups (table 2). For patients in the BB group, length of stay in the ICU and total length of stay were essentially unaffected by metoprolol. For patients in the no BB group, prophylactic metoprolol increased mean (SD) length of stay in the ICU from $31.7(18.1)$ to $53.0(107.8)$ hours $(\mathrm{p}=0.03)$. There was an increase for total length of stay from 148.0 (59.0) to $183.4(171.2)$ hours $(p=0.002)$. These differences in metoprolol effect between groups remained significant after adjustment for differences in baseline characteristics. The significant interaction between prophylactic metoprolol and preoperative use of $\mathrm{BB}$ suggests that prophylactic metoprolol affects these patient populations differently.

The rate of complications was low and not different between study groups (table 2). The hospital costs were not affected by prophylactic metoprolol in the BB group (mean (SD) C\$4755 (2040) v C\$4729 (1730)), but were significantly increased by prophylactic metoprolol in patients of the no BB group (C\$5374 (2839) v C\$4521 (1508), p = 0.009).

\section{DISCUSSION}

Patients not previously on $\mathrm{BB}$ received no benefit from prophylactic metoprolol and appear to have had worse outcomes in terms of haemodynamics, length of stay in hospital, and costs.

This observation is biologically plausible as BB withdrawal is known to create a hyperadrenergic state. If preoperative $\mathrm{BB}$ use is important for the benefits of prophylactic BB treatment to occur, then in patients without $\mathrm{BB}$ withdrawal (without history of preoperative $\mathrm{BB}$ treatment), the potential to achieve a benefit is lessened. However, the potential for BB related side effects remains.

Essentially, patients having CABG in our study were more likely to have received a $\mathrm{BB}$ preoperatively than those having valve surgery. It is unlikely that the different ratio of valve to CABG surgery between groups explains the observation of this paper. It is possible that unrecognised contraindications for BB were missed at the time of enrolment into the study, but this is unlikely given the same proportions of patients ventilated for more than three days, reintubated, or requiring a permanent pacemaker.

This study indicates that only patients with a history of BB use before the operation appear to benefit from such prophylaxis. Patients not on BB preoperatively might be considered for prophylaxis by alternative drugs or for no prophylaxis. These findings are not conclusive but are hypothesis generating and should be tested in further prospective trials.

\section{Authors' affiliations}

E Crystal, Division of Cardiology, Sunnybrook and Womens' College Health Sciences Centre, University of Toronto, Toronto, Ontario, Canada K E Thorpe, R Roberts, M Gent, Department of Clinical Epidemiology and Biostatistics, McMaster University, Hamilton, Ontario, Canada

S J Connolly, S Carroll, Department of Medicine, McMaster University A Lamy, I Cybulsky, Department of Surgery, McMaster University

Correspondence to: Dr Eugene Crystal, 2075 Bayview Avenue, Room D377, Division of Cardiology, Sunnybrook and Womens' College Health Science Centre, Toronto, Ontario, Canada; eugene.crystal@ sw.on.ca

Accepted 3 October 2003

\section{REFERENCES}

1 Eagle KA, Guyton RA, Davidoff R, et al. ACC/AHA guidelines for coronary artery bypass graft surgery: a report of the American College of Cardiology/ American Heart Association task force on practice guidelines. J Am Coll Cardiol 1999;34:1262-347.

2 Connolly SJ, Cybulsky I, Lamy A, et al. Double-blind, placebo-controlled, randomized trial of prophylactic metoprolol for reduction of hospital length of stay after heart surgery: the beta-blocker length of stay (BLOS) study. Am Heart J 2003;145:226-32. 